\title{
Naïve vs. switchers differences in treatment effectiveness in spondyloarthritis
}

\author{
Irina Andrada Craciun ${ }^{1}$, Relu Liviu Craciun ${ }^{3,4}$ Sanziana Elena Daia-Iliescu ${ }^{1,2}$, \\ Ruxandra Ionescu ${ }^{1,2}$ \\ ${ }^{1 " C a r o l ~ D a v i l a " ~ U n i v e r s i t y ~ o f ~ M e d i c i n e ~ a n d ~ P h a r m a c y, ~ B u c h a r e s t, ~ R o m a n i a ~}$ \\ 2"Sf. Maria" Clinical Hospital, Department of Internal Medicine and Rheumatology, \\ Bucharest, Romania \\ ${ }_{3}^{3} 3^{\text {rd }}$ Department, 1st Clinical Medical Disciplines, Faculty of Medicine, \\ "Ovidius" University, Constanta, Romania \\ ${ }^{4} 1$ st Internal Medicine Clinic, "Sf. Apostol Andrei" Emergency Clinical County Hospital, \\ Constanta, Romania
}

\begin{abstract}
Introduction. Treat-to-target concept in spondyloarthritis $(\mathrm{SpA})$ is a highly disputed subject. Up to the present there is no evaluation score that integrates the clinical and laboratory/imaging results for defining remission in $\mathrm{SpA}$. This issue generates the need of identifying predictive factors of remission in SpA patients.

Aim. The aim of this study is to assess the effectiveness of the biological treatment upon naïve patients versus switchers and to identify some difficulties in achieving remission.

Material and method. 65 patients with SpA were enrolled in this retrospective study, using data from multiple-choice forms and medical reports from University Hospitals in Romania, between 2019-2021.

Results. 65 patients with SpA, in treatment with one biological disease-modifying antirheumatic drug (bDMARD) were available for the baseline analysis. They were distributed into 3 groups, whether they changed the biological therapy: group 1 - naïve patients, group 2 - first-time switchers and group 3 - more than one-time switchers. BASDAI and ASDAS were calculated at baseline, 24 and 52 weeks for the 3 groups. The scores were higher for the switchers and the highest in the 3rd group. Retention time of the first bDMARD was compared between groups and between the biological therapies.

Conclusions. Results showed that the best treatment response, as well as effectiveness, is reached by the naïve patients group. Greater retention time rate for the first bDMARD is associated with a greater chance of achieving remission.
\end{abstract}

Keywords: treat-to-target, spondyloarthritis, remission, effectiveness

\section{INTRODUCTION}

Biological treatment offered new perspectives of chronic inflammatory rheumatic diseases, including spondyloarthritides. These therapies completely changed the natural history of SpA, increasing the quality of life. However, scientific groups have not reached yet a common conclusion concerning the remission, using the concept of "treat-to-target", widely used for other chronic diseases [1,2]. It is difficult to put together and define clinical and paraclinical remission in SpA, only few patients succeded in achieving both in clinical trials [3].

\section{OBJECTIVES}

The objective of this study is to assess the effectiveness of the therapy, as well as to identify some difficulties in achieving remission in SpA.

\section{MATERIAL AND METHOD}

This is a retrospective study that included a number of 65 patients were evaluated using a multiplechoice form and medical reports, from Internal Medicine clinics from University hospitals in Bucharest and Constanta, Romania, between November 2019 
and May 2021. Inclusion criteria were: age between 20 and 75 years, signed inform consent, a diagnosis of AxSpA, using ASAS criteria, who were on biological treatment. Medical records were reviewed for information on demographic features, disease subtype (axial and/or peripheral), smoking status, comorbidities, peripheral involvement, disease activity. Laboratory and imaging findings were reviewed at the time of treatment initiation and at 24 and 56 weeks thereafter. The form included questions concerning the patients" opinion regarding the activity of their disease with the current treatment.

Quantitative variables were described using descriptive statistics (mean, median, quartiles, minimum, maximum), Lillefors corrected test or histograms in order to test the normal distribution. Continuous variables with normal distribution were analyzed using t Student test for 2 variables or ANOVA for 3 variables. Continuous variables with nonnormal distribution were analyzed with non-parametric tests - Mann-Whitney U and Kruskal-Wallis for correlations between two or more groups. Categorial variables were expressed as absolute value/percent and they were analyzed using $\chi^{2}$ or Fisher test.

Statistical tests were run using IBM SPSS, version 20.0 and Python, version 3.0.

\section{RESULTS}

65 patients were enrolled in this study, all of them were on biological treatment. They were divided in 3 groups, depending on whether they had switched biological agents: naive (36 patients, group 1), first-time switchers (19 patients, group 2) and more than onetime switchers (10 patients, group 3: 4/10 on 3rd agent, $3 / 10$ on 4 th agent, $3 / 10$ on 5 th agent and 1/10 on 6 th agent). Table 1 displays the demographic and disease characteristics. Mean age in group 1 was $44.25 \pm 11.726$ years, in group 2 was $46.89 \pm 12.578$ years, in group 3 was $48.20 \pm 11.448$ years.

All the patients received bDMARDs, most of them Etanercept (original or biosimilars - 33/65 patients) and some of them received NSAIDs (24/65) or cDMARDs (methotrexate and/or sulfasalazine $7 / 65)$.

The following step was to assess the disease activity between the three groups, defined using BASDAI, ASDAS-PCR and the values of CRP and ESR (figure 1). $18 / 36$ naive patients, $9 / 19$ first-time switchers and only $1 / 10$ of the more than one-time switchers achieved remission during the present treatment, defined as ASDAS-CRP $<1.3$. From those who did not
TABLE 1. Demographic and disease characteristics

\begin{tabular}{|c|c|c|c|}
\hline & $\begin{array}{l}\text { Naive - } \\
\text { group } 1\end{array}$ & $\begin{array}{c}\text { First-time } \\
\text { switchers - } \\
\text { group } 2\end{array}$ & $\begin{array}{l}\text { More than } \\
\text { one-time } \\
\text { switchers - } \\
\text { group } 3\end{array}$ \\
\hline $\begin{array}{l}\text { Age (years, } \\
\text { mean } \pm S D \text { ) }\end{array}$ & $44.25 \pm 11.726$ & $46.89 \pm 12.578$ & $48.20 \pm 11.448$ \\
\hline Gender (males) & 28 & 13 & 7 \\
\hline Smoker & 10 & 2 & 2 \\
\hline $\begin{array}{l}\text { Disease duration } \\
\text { (years, mean SD) }\end{array}$ & $11.6 \pm 6$ & $13.02 \pm 8.29$ & $13.5 \pm 7$ \\
\hline $\begin{array}{l}\text { BASDAI present } \\
\text { (mean, } \pm \text { SD) }\end{array}$ & $0.75 \pm 0.6$ & $1.41 \pm 1.97$ & $3.67 \pm 2.69$ \\
\hline $\begin{array}{l}\text { ASDAS present } \\
\text { (mean, } \pm \text { SD) }\end{array}$ & $1.24 \pm 0.46$ & $1.5 \pm 1.11$ & $2.82 \pm 1.4$ \\
\hline $\begin{array}{l}\text { BASDAI baseline } \\
\text { (mean, } \pm \text { SD) }\end{array}$ & $6.59 \pm 1.03$ & $6.5 \pm 1.1$ & $6.56 \pm 1.13$ \\
\hline $\begin{array}{l}\text { ASDAS baseline } \\
\text { (mean, } \pm \text { SD) }\end{array}$ & $4.01 \pm 0.6$ & $4.09 \pm 0.87$ & $4.16 \pm 0.63$ \\
\hline Treatment & $\begin{array}{c}24 / 36 \\
\text { Etanercept } \\
8 / 36 \\
\text { Adalimumab } \\
2 / 36 \\
\text { Infliximab } \\
1 / 36 \\
\text { Golimumab } \\
1 / 36 \\
\text { Secukinumab }\end{array}$ & $\begin{array}{c}7 / 19 \\
\text { Etanercept } \\
7 / 19 \\
\text { Golimumab } \\
3 / 19 \\
\text { Adalimumab } \\
1 / 19 \\
\text { Secukinumab } \\
1 / 19 \\
\text { Infliximab }\end{array}$ & $\begin{array}{c}4 / 10 \\
\text { Golimumab } \\
2 / 10 \\
\text { Etanercept } \\
2 / 10 \\
\text { Certolizumab } \\
2 / 10 \\
\text { Secukinumab }\end{array}$ \\
\hline
\end{tabular}

achieved remission, more than one-time switchers had the highest disease activity rates (high and very high, ASDAS-CRP > 2.1).

The effectiveness of the biological treatment was assessed using BASDAI and ASDAS scores from the moment of data collection, as well as at the beginning of the treatment, 24 weeks ( 6 months) and 52 weeks (12 months), which are mandatory for treatment initiation (figure 2).

The distribution of ASDAS and BASDAI between the 3 groups was showed to be different: naive patients (group 1) and one-time switchers (group 2) had constantly decreased values, which meant they responded well to treatment. For more than one-time switchers (group 3), it is more difficult to maintain low levels of BASDAI and ASDAS. BASDAI difference between the 3 groups had $p$ value $=0.01$, ASDAS $p$ value $=0.02$, so there was a statistically significant difference (figures 2, 3 and 4).

Another factor which was tested was the drug survival rate for the first bDMARD. More than half of patients first started with Etanercept (original or biosimilars) in all groups, whereas in group 2 and 3, Etanercept and Infliximab were preferred. The mean duration of follow-up was 61.84 months, with a SD of 43.263 for all the 61 patients (those at initiation 


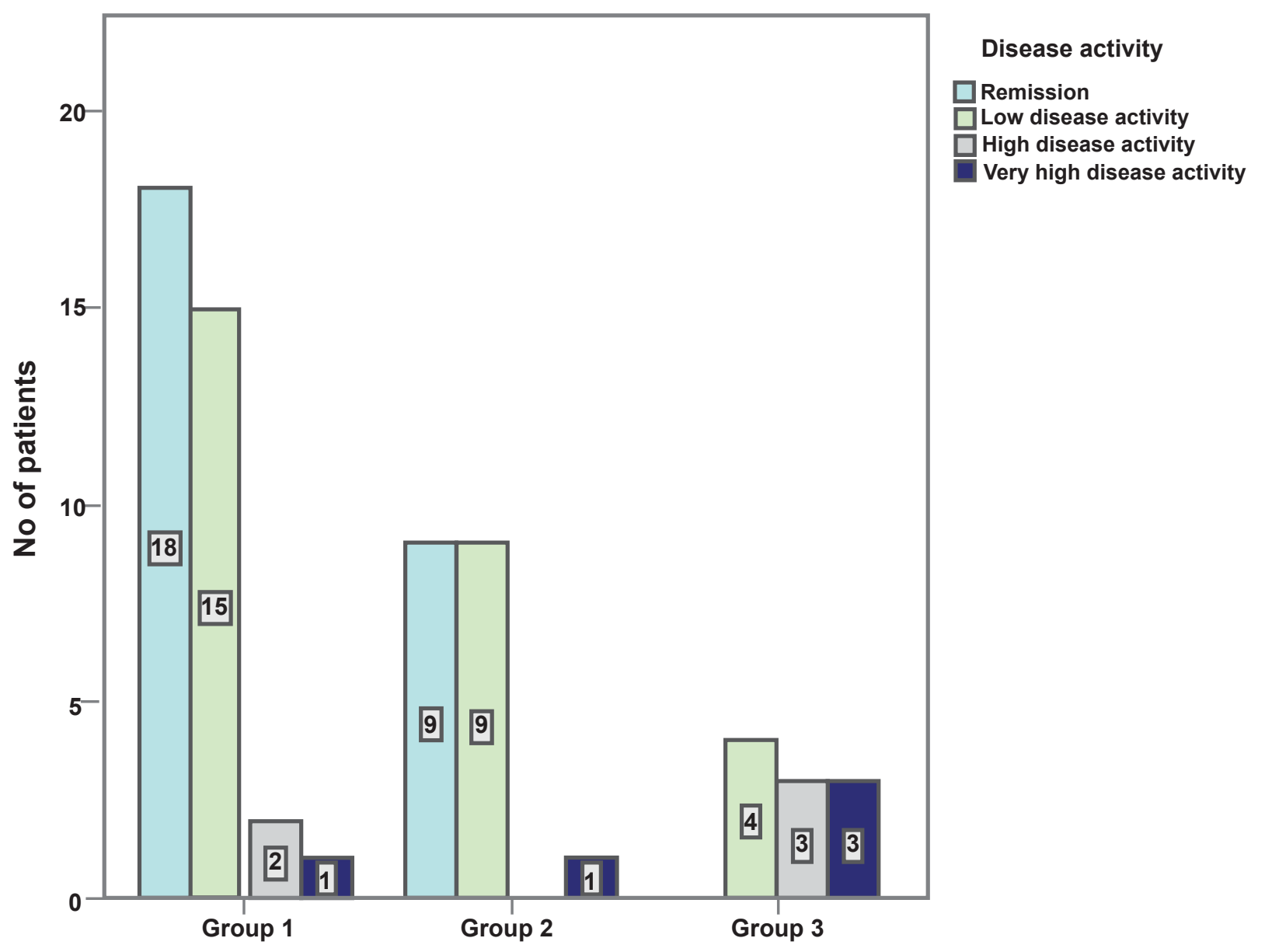

FIGURE 1. Disease activity by groups (group 1 - naïve patients, group 2 - first-time switchers, group 3 - more than onetime switchers)

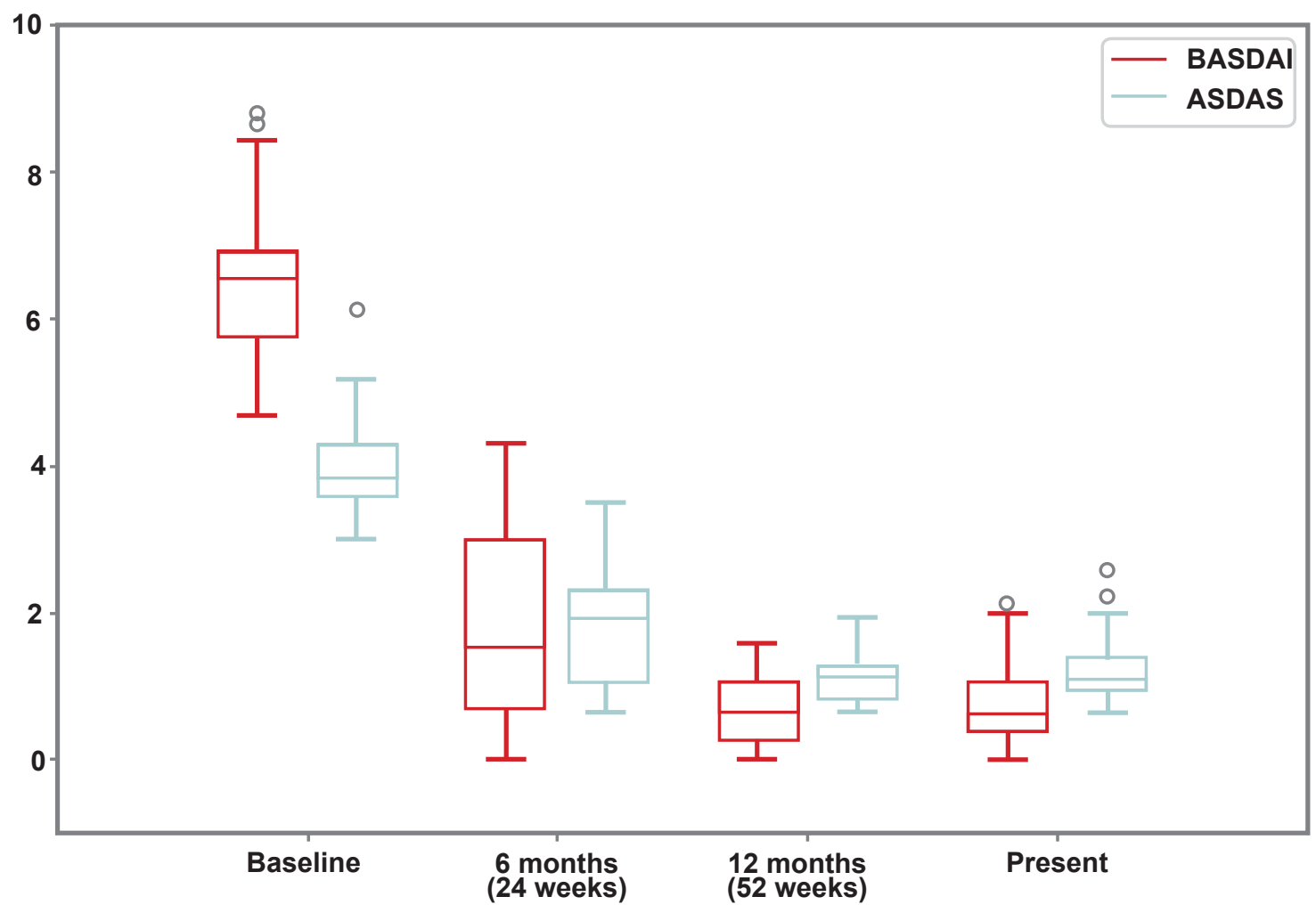

FIGURE 2. BASDAI and ASDAS evolution between 0 and 52 weeks after treatment initiation for group 1 (naïve patients) 


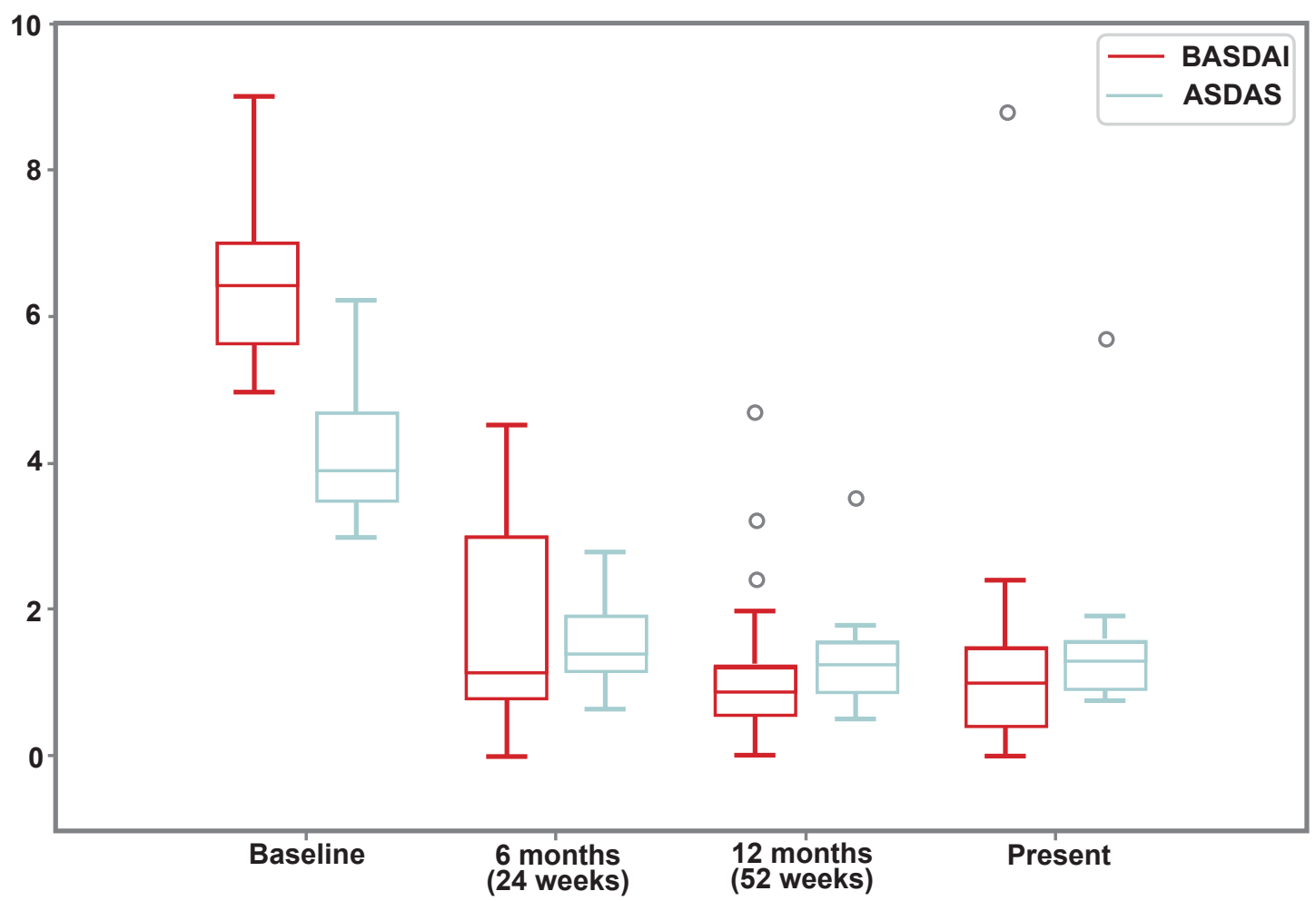

FIGURE 3. BASDAI and ASDAS evolution between 0 and 52 weeks after treatment initiation for group 2 (first-time switchers)

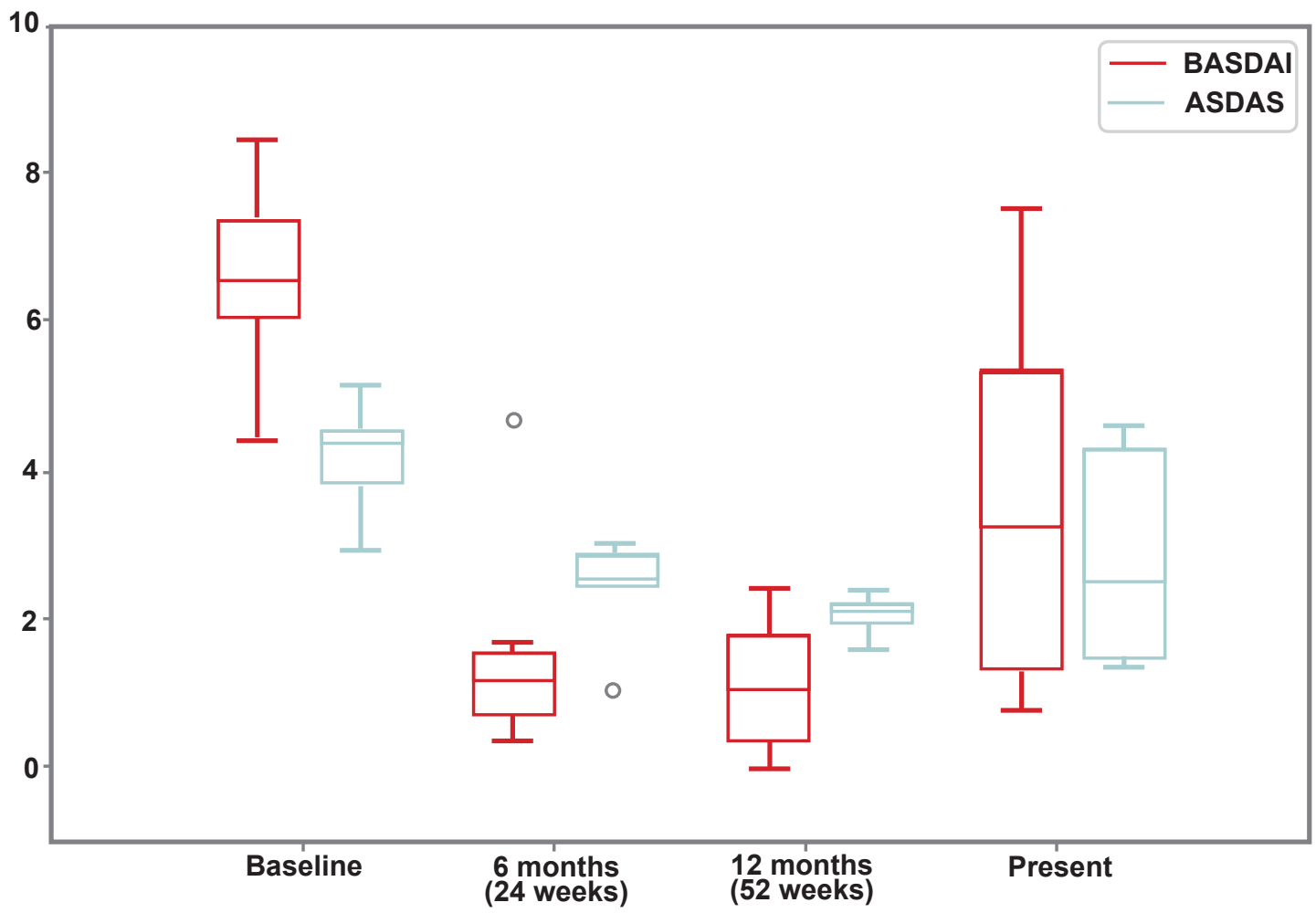

FIGURE 4. BASDAl and ASDAS evolution between 0 and 52 weeks after treatment initiation for group 3 (more than onetime switchers)

and those whose treatment was under 6 months were excluded).

The results showed a statistical significance between group 1 (naïve patients) -75.97 months \pm 47.49 and group 2 (first-time switchers) $-47.94 \pm 25.49, \mathrm{p}$ value $=0.005$ (figure 5).

Concerning the impact of the first bDMARDs in achieving remission or low disease activity, Infliximab 


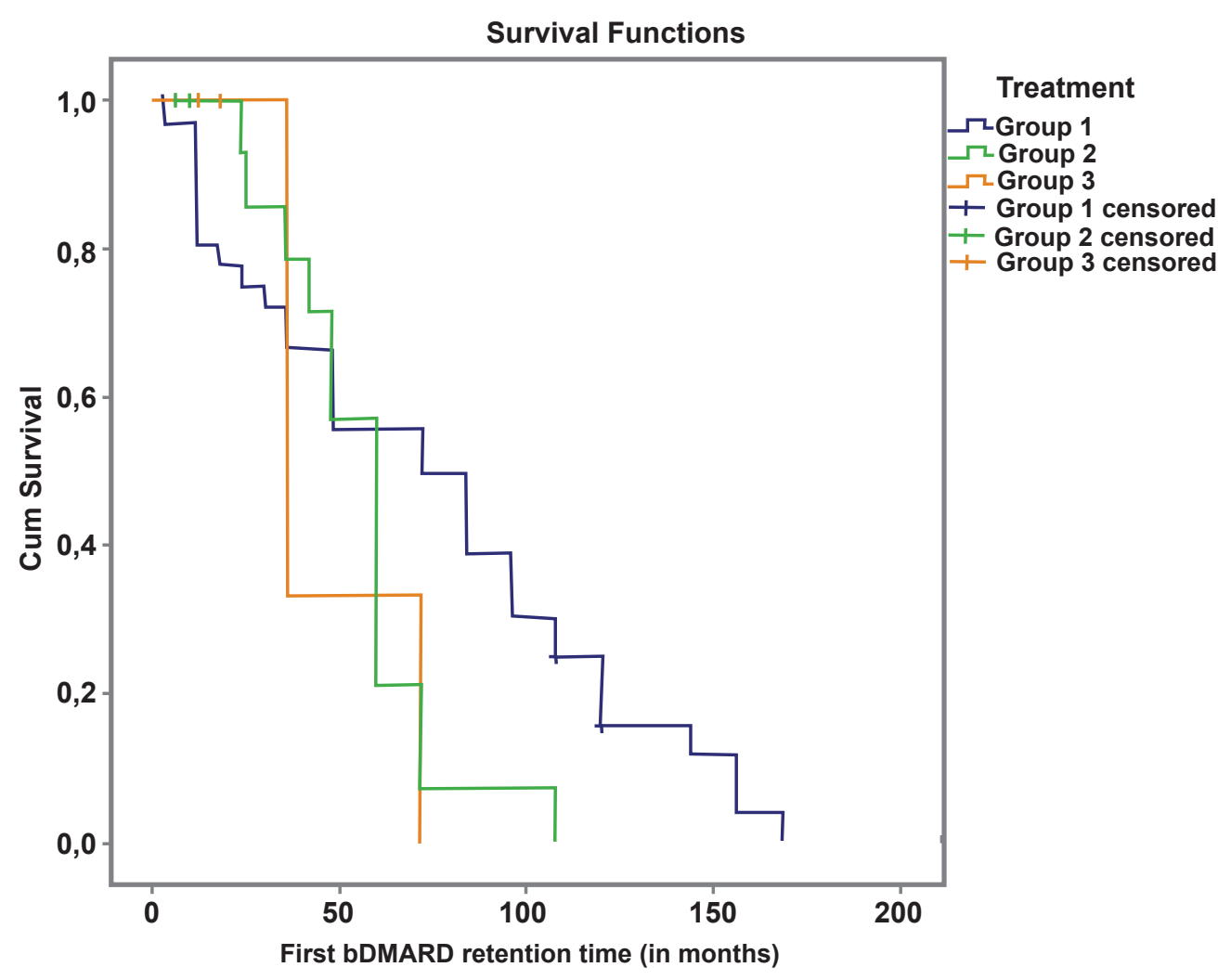

FIGURE 5. Retention time of first bDMARD in relation with the 3 groups (naïve, first-time switchers, more than one-time switchers)

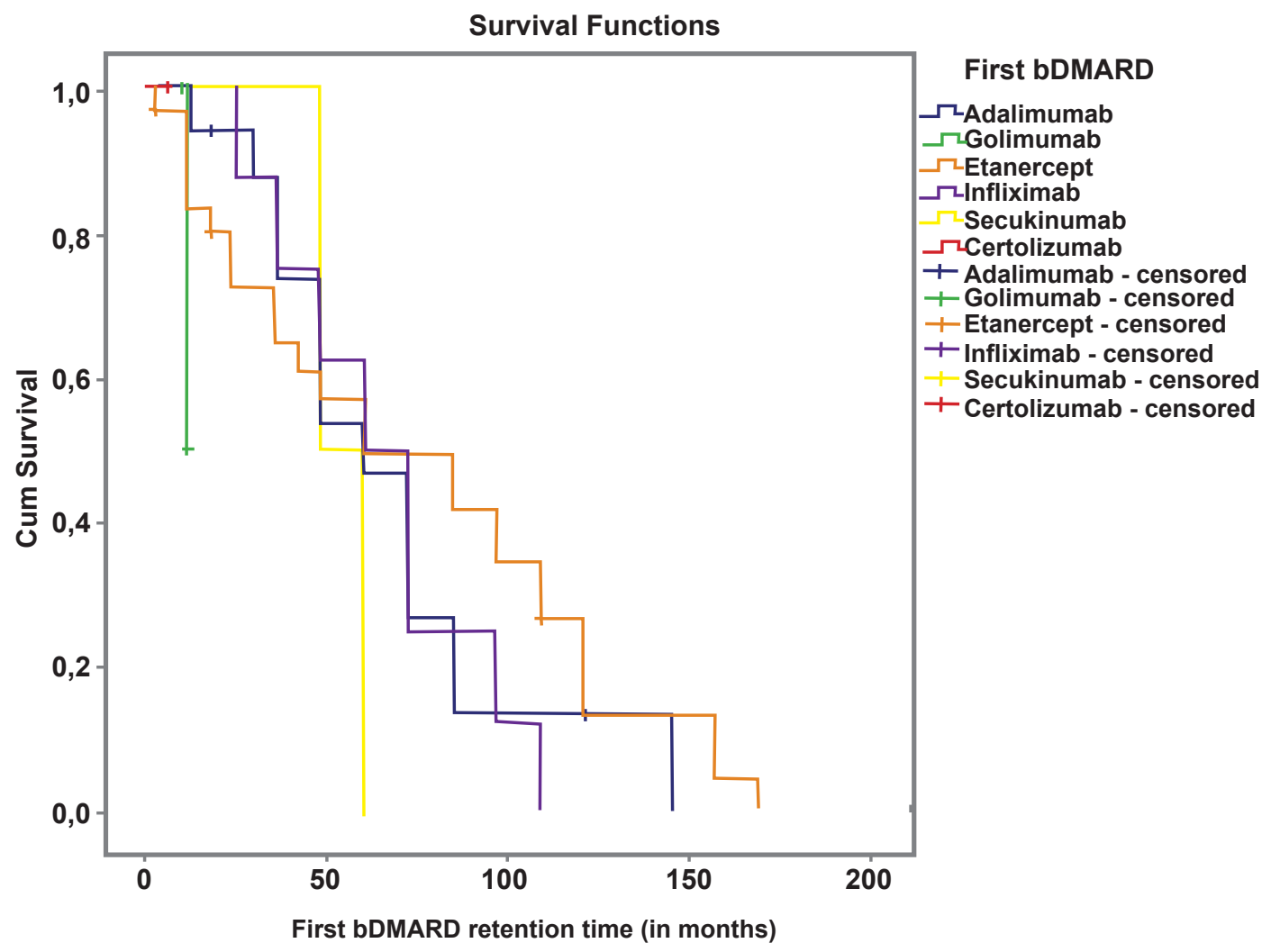

FIGURE 6. Retention time of first bDMARD

had the longest mean retention time, $64.63 \pm 28.440$, median 66 months, followed by Etanercept with $63.48 \pm 51.393$ months, median 48. By contrast, Cer- tolizumab had only 6 months of retention time, followed by Golimumab, with $11.33 \pm 1.155$ months, median 12 months (figure 6). 


\section{DISCUSSION}

It is very difficult to accept a universal definition for remission in $\mathrm{SpA}$ [4]. Remission/inactive disease is defined as the absence of symptoms, as well as the absence of laboratory markers of disease. Even though there is no BASDAI cut-off value for remission, clinical trials used different ones $(<4,<3, \leq 3)$. BASDAI is a subjective score because it uses only the patients' evaluation of disease. ASDAS offers a more objective evaluation of the disease activity because it includes CRP and/or ESR, which may represent predictive factors of structural progression. The disease activity using ASDAS (inactive, moderate activity, high and very high activity) was validated for use in clinical trials, as well as in assessing the treatment response. None of the composite scores integrated imaging findings in defining remission [5]. However, it is necessary to create a new score which will include structural progression and the quality of life, which represents the major challenge in "treatto-target" in SpA. Moreover, there are differences between doctor's opinion and that of the patient's concerning the activity of the disease, the severity, and the treatment. Some studies showed that the cutoff value of ASDAS was higher for patients (ASDAS $\leq 2.2)$ than doctors (ASDAS $\leq 2)[6]$.

Long-term clinical trials for bDMARDs effectiveness using TNF-alpha inhibitors showed similar results, up to $40 \%$ patients achieved remission for 8 years (the current study has $43.07 \%$ ) [7,8].

Another retrospective study which analyzed partial remission in patients treated with TNF-alpha inhibitors showed that the probability of achieving re-

Conflict of interest: none declared

Financial support: none declared

\section{REFERENCES}

1. Dougados M. Treat to target in axial spondyloarthritis: From its concept to its implementation. J Autoimmun. 2020 Jun;110:102398.

2. van der Heijde $D$, Ramiro $S$, Landewé $R$, Baraliakos $X$, Van den Bosch F, et al. 2016 update of the ASAS-EULAR management recommendations for axial spondyloarthritis. Ann Rheum Dis. 2017 Jun;76(6):978-991.

3. Sieper J. How to define remission in ankylosing spondylitis? Ann Rheum Dis. 2012 Apr;71 Suppl 2:i93-5.

4. Baraliakos X, Berenbaum F, Favalli EG, Olivieri I, Ostendorf $B$, Poddubnyy D, DE Vlam K. Challenges and Advances in Targeting Remission in Axial Spondyloarthritis. J Rheumatol. 2018 Feb;45(2):153-157.

5. Song $\mathrm{IH}$, Hermann K, Haibel H, Althoff CE, Listing J, et al. Effects of etanercept versus sulfasalazine in early axial spondyloarthritis on active inflammatory lesions as detected by whole-body MRI (ESTHER): a 48-week randomised controlled trial. Ann Rheum Dis. 2011 Apr;70(4):590-6.

6. Godfrin-Valnet M, Prati C, Puyraveau M, Toussirot E, Letho-Gyselink $H$, Wendling $D$. Evaluation of spondylarthritis activity by patients and mission is lower for switchers $(57.6 \%$ of naive patients and $40.5 \%$ of switchers, $p=0.0039$ ) [9].

Current studies focus only on investigating predictive factors associated with remission in patients treated with one bDMARD (TNF-alpha inhibitors or IL-17 inhibitors) and not both.

A similar result for drug survival rates was obtained in one study which compared naive patients with switchers, and the retention rate of the first bDMARD was 43 (23-67) months for the naive and 20 (10-33) for the switchers, with a $\mathrm{p}$ value $<0.001$ [10].

This study has a series of limitations which may have influenced the statistical significance of the results. Firstly, medical reports are a very important resource of information, but some of them are not complete or missing. Secondly, the cohort was very heterogenous and made the statistical processing harder (diagnosis time, duration of disease, present bDMARD, smoking status etc.). One of the future directions for research could be the extension of the study to many more patients, using nationwide and international registries in order to conduct a prospective study which may include demographic and clinical data, as well as clinical exam data and laboratory/ imaging findings.

\section{CONCLUSIONS}

In the current study, patients who had a lower survival drug rate for the first bDMARD had a lower chance to achieve remission. Patients who switched more bDMARDs were more unlikely to achieve remission than naive ones. physicians: ASDAS, BASDAI, PASS, and flares in 200 patients. Joint Bone Spine. 2013 Jul;80(4):393-8.

7. Baraliakos X, Haibel H, Fritz C, Listing J, Heldmann F, Braun J, Sieper J. Long-term outcome of patients with active ankylosing spondylitis with etanercept-sustained efficacy and safety after seven years. Arthritis Res Ther. 2013;15(3):R67.

8. Baraliakos X, Listing J, Fritz C, Haibel H, Alten R, Burmester GR, Krause $A$, et al. Persistent clinical efficacy and safety of infliximab in ankylosing spondylitis after 8 years - early clinical response predicts long-term outcome. Rheumatology (Oxford). 2011 Sep;50(9):1690-9.

9. Spadaro A, Lubrano E, Marchesoni A, D'Angelo S, Ramonda R, Addimanda O, Perrotta FM, Olivieri I, Punzi L, Salvarani C. Remission in ankylosing spondylitis treated with anti-TNF- $\alpha$ drugs: a national multicentre study. Rheumatology (Oxford). 2013 Oct;52(10):1914-9.

10. Lee JW, Kang JH, Yim YR, Kim JE, Wen L, Lee KE, Park DJ, Kim TJ, Park YW, Lee SS. Predictors of Switching Anti-Tumor Necrosis Factor Therapy in Patients with Ankylosing Spondylitis. PLoS One. 2015 Jul 15;10(7):e0131864. 